\title{
Economic report on the cost of dengue fever in Vietnam: case of a provincial hospital
}

Luyen Dinh Pham

Nhat Huy Tran Phung

Nguyen Tu Dang Le

Trung Quang Vo

Department of Pharmacy

Administration, Faculty of Pharmacy,

University of Medicine and Pharmacy,

Ho Chi Minh City, Vietnam
Correspondence: Trung Quang Vo Department of Pharmacy Administration, Faculty of Pharmacy, University of Medicine and Pharmacy, 4I Dinh Tien Hoang Street, Ben Nghe, District I, Ho Chi Minh City 700000, Vietnam

$\mathrm{Tel}+84838295641$

Fax +84838225435

Email voquangtrungdk@gmail.com
This article was published in the following Dove Press journal:

ClinicoEconomics and Outcomes Research

16 December 2016

Number of times this article has been viewed

Background: Dengue is a mosquito-borne viral illness with the world's fastest rate of infection. In 2014, Vietnam had recorded 43,000 cases in 53 provinces, with 28 deaths.

Materials and methods: A 6-month cross-sectional study was conducted from September 2015 to March 2016 at $\mathrm{Cu}$ Chi General Hospital. Cost of illness in this study was estimated under the incidence-based approach from the societal perspective.

Results: The average cost per case was US\$139.3 $\$$ \$61.7. The average cost per child was higher than per adult, but not significant $(\$ 151.0 \pm \$ 63.5$ and $\$ 132.7 \pm \$ 59.9$, respectively; $P=0.068)$. Meanwhile, $50.2 \%$ of the total cost was contributed by the cost of hospital bed. According to the sensitivity analysis, if both the costs of the hospital bed and ultrasound were reduced by $10 \%$, the total treatment cost of dengue fever would fall by $5 \%$ and $1.6 \%$, respectively.

Conclusion: This study is expected to be the basis for investment-plan formulation and fund allocation for the treatment and prevention of dengue. In an attempt to examine the entire socioeconomic encumbrance caused by the dengue virus, a larger scale study targeting both dengue and dengue hemorrhagic fever needs to be conducted in several hospitals.

Keywords: cost of illness, dengue, dengue fever, hospital, Vietnam

\section{Introduction}

Dengue is known for being the world fastest-spreading infectious mosquito-borne viral illness, ${ }^{1}$ which varies itself into four genetically distinct dengue virus serotypes, namely DEN1, DEN2, DEN3, and DEN4, of the genus Flavivirus, and is transmitted by Aedes aegypti and A. albopitus mosquitoes. ${ }^{2,3}$ These virus variants cause dengue with a great range of symptomatic expressions, including dengue fever (DF) and severe dengue. ${ }^{1,4}$ The tropics and subtropics are highly susceptible to the disease, and local virus variations are likely to happen due to certain propitious environmental factors, such as temperature and rainfall, as well as uncontrolled fast-paced urbanization. ${ }^{5}$ Children are at a higher risk of severe dengue. ${ }^{6}$ Sequential heterotypic infections are also common in dengue-endemic areas. ${ }^{7}$

Not until 1970 had nine countries undergone dengue epidemics. ${ }^{8}$ Nevertheless, over 100 countries in the World Health Organization (WHO) regions of Africa, America, Eastern Mediterranean, Southeast Asia, and Western Pacific have now experienced it as endemic. ${ }^{9}$ A recent estimate indicates 390 million dengue infections per year, of which 96 million (67-136 million) manifest clinically (with any severity of disease). ${ }^{1}$ According to the WHO's announcement in 2015, dengue has spread in many countries, especially in the Asia-Pacific region, with a record of 85,488 cases. $^{10}$ In 2014, Vietnam recorded 43,000 cases in 53 provinces, with 28 submit your manuscript Dovepress if in $>$ 
deaths. ${ }^{11}$ Okanurak et al found the average treatment cost per case was US\$118 for children and \$161 for adults in Thailand in 1997. ${ }^{12}$ Meanwhile, in Mexico in 2011, Eduardo et al estimated the average cost for an episode of nonlethal dengue was \$1,327 for hospitalized and \$451 for ambulatory patients. ${ }^{15}$ Furthermore, Tam et al showed middling expenses for dengue treatment in Can Tho province, Vietnam, at $\$ 167.77 \pm \$ 141.74$ compared to $\$ 61.36$ in Ho Chi Minh City in 2005. ${ }^{13,14}$ Annual cost, including surveillance and vector control, was $\$ 170$ (95\% confidence interval [CI]: \$151-\$292) million or \$1.56 (95\% CI: \$1.38-\$2.68) per capita in Mexico between 2010 and 2011. ${ }^{15}$ According to Edillo et al, the direct medical cost associated with dengue was $\$ 345$ million or $\$ 3.26$ per capita in the Philippines in $2015 .{ }^{16}$ To provide accurate and timely information about the economic impacts of DF, this study endeavors to present treatment costs from a societal perspective at $\mathrm{Cu} \mathrm{Chi}$ General Hospital, Vietnam.

\section{Materials and methods Study site}

$\mathrm{Cu}$ Chi district is located in northwest Ho Chi Minh City, southern Vietnam, and accounts for $20.74 \%$ of the acreage of the entire city at a distance of $50 \mathrm{~km}$ from the city center. ${ }^{17} \mathrm{Cu} \mathrm{Chi}$ is the economic, political, and cultural center of the district, with a tropical monsoon climate, equatorial nature, wet season from April to November, and average yearly rainfall of $1,535 \mathrm{~mm}$. This study was conducted at $\mathrm{Cu}$ Chi General Hospital, a level II hospital with a capacity of 1,000 beds. $^{18}$

\section{Study design}

In this study, cost-of-illness estimates followed the incidence-based approach from the societal perspective of cost of illness of DF. ${ }^{19}$ The study-sample formula was based on Lemeshow et al study. ${ }^{20} \mathrm{~A}$ pilot study was carried out with 12 patients, ${ }^{21}$ where results showed that the standard deviation of the cost of treatment of dengue was $\$ 28.92$ $\left(d=\$ 4.5,95 \%\right.$ CI associated with $Z_{1-\alpha / 2}=1.96$, refusal rate $5 \%$ ). After the calculation with the formulation, the sample size was 166 patients. In the process of collecting data, there may have been some cases to cause bias, so the sample size was expanded to 170 patients. The study was conducted for about 6 months between September 2015 and March 2016 at $\mathrm{Cu}$ Chi General Hospital. While analyzing the data of 170 patients, we found two cases of noncompliance with treatment guidelines; therefore, we analyzed data on 168 patients.

\section{Data collection}

The population of this study consisted of patients with a diagnosis based on the WHO's International Classification of Diseases (ICD)-10, codes A90-A91, during the selection window (Figure 1). ${ }^{1,22}$ Research assistants interviewed patients or their caregivers using a structured questionnaire from a previous study in Vietnam ${ }^{23}$ to gather information about the socioeconomic circumstances and health-seeking behavior of patients, expense information associated with the illness episode and the clinical diagnosis, and direct medical costs of each enrolled patient by querying the $\mathrm{Cu}$ Chi General Hospital electronic database. The study process had two steps: 1) in the face-to-face survey, general characteristics of participants (age, sex, occupation, income, history of disease, etc) and treatment cost, including prehospitalization and hospitalization periods, were collected; and 2) in the follow-up telephone interview, research assistants conducted telephone interviews with patients or any members of their family with good understanding about the illness and the relevant expenses needed to treat dengue symptoms within 7-10 days posthospitalization. The duration of dengue was defined from the day first occurrence of dengue symptoms until the day of complete disappearance of said symptoms. If a patient still had symptoms on the first follow-up telephone call, a further call at 7-10 days after was conducted.

\section{Cost components}

Cost-of-illness estimates in this study were incidence-based from a societal perspective, ${ }^{19}$ and hence considered all costs, irrespective of who incurred them. The costs consisted of direct and indirect costs.

\section{Direct cost components}

Direct cost in this study included direct medical cost and direct nonmedical cost. ${ }^{19}$ Medical service-utilization data included costs of hospital bed, laboratory tests, operation, pharmaceutical, medical material, informal payments incurred, and the health care system in the prehospitalization, hospitalization, and posthospitalization periods. Unit costs of medical services were measured with reference to Trung et al. ${ }^{24}$ Self-reported illness-related nonmedical cost items, such as meals, transport, accommodation, and informal care costs, were collected from patients and their family members.

\section{Indirect cost components}

Indirect costs or loss of production are defined as costs that occur to society related to loss of production, due either to the disease or its treatment. ${ }^{19}$ Studies generally distinguish 


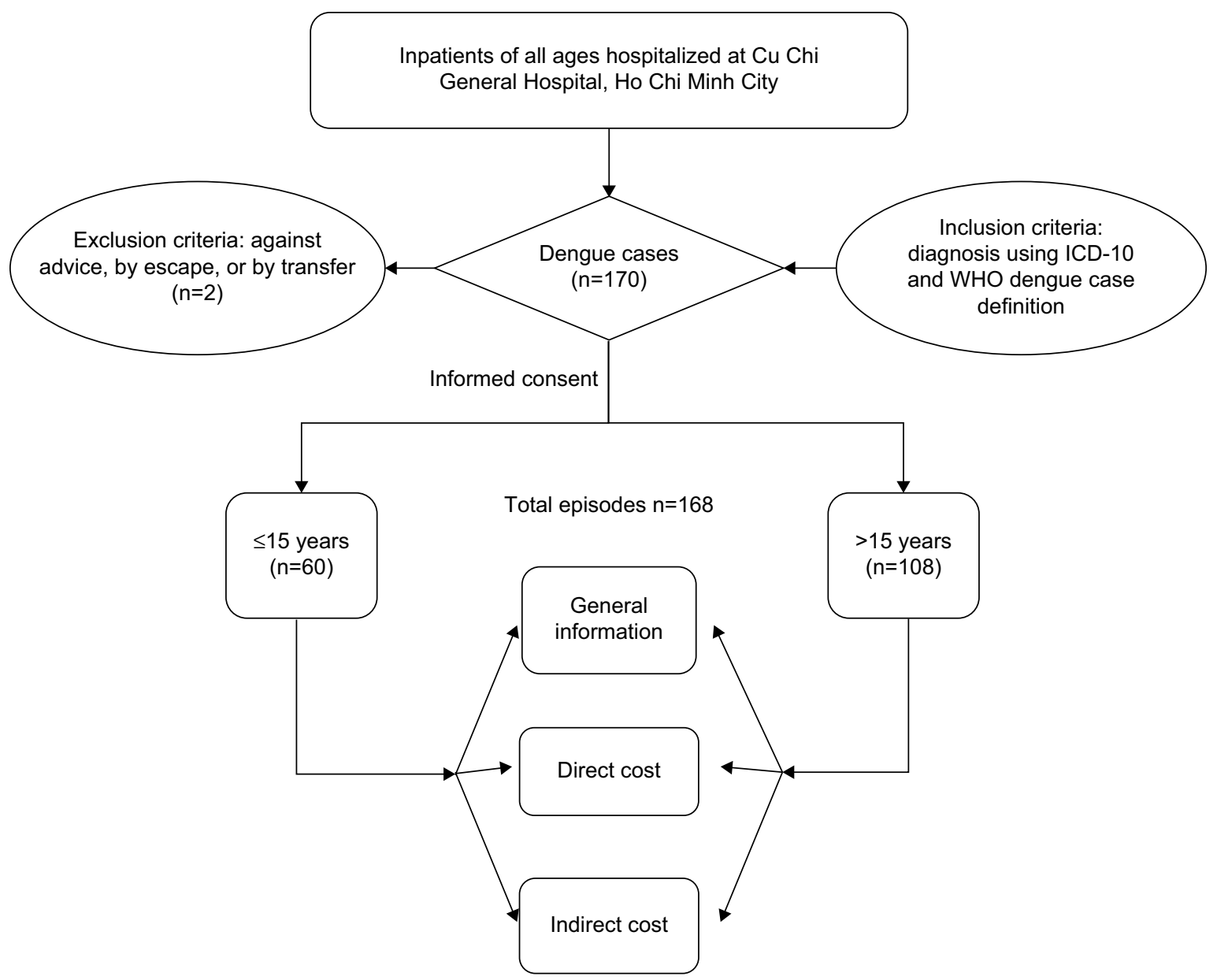

Figure I Selection and classification of patients studied.

Abbreviations: ICD, International Classification of Diseases; WHO, World Health Organization.

among short-term work, school, or other activity losses due to sickness absence.

\section{Data analyses}

Analyses were conducted at the episode level, and thus included patients with one or more episodes. All analyses were conducted using descriptive statistics using Microsoft Excel 2013, used to calculate the demographic characteristics and mean costs with standard deviation. Subgroup analysis of dengue costs was performed based on a previous study in Vietnam, ${ }^{23}$ eg, patient age $\leq 15$ years and $>15$ years. When relevant, appropriate statistical tests were used to compare subgroup panels to determine among these groups whether significant differences in cost of treatment existed by using the Kruskal-Wallis test and Wilcoxon test. ${ }^{25,26}$ Statistical significance was considered when $P<0.05$. A sensitivity analysis was performed using the average cost of the case series as the baseline cost of illness, and upper and lower scenarios were developed for patient care to determine the impact on the total cost. In order to avoid bias, patients who died prematurely were excluded from the data-analysis set. All costs were measured in terms of Vietnamese currency (dong [ $\underline{\mathrm{d}}]$ ) and converted to US dollars using the exchange rate with $\$ 1=₫ 21.833 .^{27}$

\section{Ethical consideration}

Written informed consent was obtained from adult participants and parents or guardians on behalf of children participants involved in the study and before specimen collection and questionnaire survey. The research protocol was approved by the biomedical research ethics council at the University of Medicine and Pharmacy, Ho Chi Minh City.

\section{Results}

The proportion of adults suffering from DF (64.3\%) is on the rise and almost double that of children (35.7\%), despite the prevalence of infection in children in recent years. Epidemiological factors of sex and morbidity were essentially not correlated with each other by statistical cause. The results showed that the percentage of mobility between men and women was relatively even (49.4\% and 50.6\%) (Table 1$)$. 
Table I Demographic characteristics of enrolled patients $(n=\mid 68)$

\begin{tabular}{|c|c|c|}
\hline Characteristic & Value & $\%$ \\
\hline \multicolumn{3}{|l|}{ Age (years) } \\
\hline Mean \pm SD & $23.2 \pm 13.3$ & \\
\hline$\leq 15$ & 60 & 35.7 \\
\hline$>15$ & 108 & 64.3 \\
\hline Range & $4-78$ & \\
\hline \multicolumn{3}{|l|}{ Sex } \\
\hline Male & 83 & 49.4 \\
\hline Female & 85 & 50.6 \\
\hline \multicolumn{3}{|l|}{ Occupation } \\
\hline Student & 67 & 39.9 \\
\hline Farmer & 8 & 4.8 \\
\hline Worker & 55 & 32.7 \\
\hline State official & 10 & 6 \\
\hline Businessman & 2 & 1.2 \\
\hline Domestic & 10 & 6 \\
\hline Other & 16 & 9.4 \\
\hline \multicolumn{3}{|l|}{ History of dengue } \\
\hline Yes & 12 & 7.1 \\
\hline No & 156 & 92.9 \\
\hline \multicolumn{3}{|c|}{ Health insurance (\%) } \\
\hline 0 & 42 & 25 \\
\hline 50 & 7 & 4.2 \\
\hline 80 & 105 & 62.5 \\
\hline 95 & 4 & 2.4 \\
\hline 100 & 10 & 5.9 \\
\hline \multicolumn{3}{|l|}{ Income (US\$) } \\
\hline Mean \pm SD & $202 \pm 74$ & \\
\hline Ensure living quality & 122 & 72.6 \\
\hline \multicolumn{3}{|c|}{ Days lost (mean \pm SD) } \\
\hline \multicolumn{3}{|c|}{ Patient } \\
\hline Prehospitalization & $1.8 \pm 1$ & \\
\hline Hospitalization & $5.2 \pm 2.1$ & \\
\hline Posthospitalization & $3.6 \pm 2.4$ & \\
\hline Total & $7.8 \pm 2.9$ & \\
\hline Caregiver & $7.6 \pm 2.1$ & \\
\hline
\end{tabular}

Abbreviation: SD, standard deviation.

Patient with DF is one of the beneficiaries for health insurance as prescribed by the Ministry of Health of Vietnam. Depending on the type of health insurance, patients with insurance will be paid different percentages. While a quarter of survey patients were not entitled to health insurance, the remaining three-quarters are paid most of the cost of $80 \%$ $(62.5 \%)$, and only a small percentage (about 5.9\%) was $100 \%$ covered by insurance for costs. Days lost for patients and caregivers were $7.8 \pm 2.9$ and $7.6 \pm 2.1$ days, respectively.

Those treated at a private clinic before hospitalization amounted to $43.5 \%$ of patients (Table 2). Prehospitalization treatment in pharmacy was nearly $40 \%, 16 \%$ received no prehospitalization treatment, and only one case reported self-medication. For laboratory tests, total blood-cell analysis by laser counter (22TS) had the highest percentage use (over 85\%), followed by rapid-test dengue NS1 Ig, AST/ALT,
Table 2 Health care center prehospitalization period and generally used medical service in the treatment of dengue

\begin{tabular}{lll}
\hline Characteristic & $\mathbf{n}$ & $\%$ \\
\hline Prehospitalization health care center & & \\
Private clinic & 73 & 43.5 \\
Pharmacy & 67 & 39.9 \\
Self-medication & $\mathrm{I}$ & 0.6 \\
No treatment & 27 & 16 \\
Laboratory test & & \\
Total blood-cell analysis by laser counter (22TS) & 144 & 85.7 \\
AST/ALT & 123 & 73.2 \\
Electrolytes (Na, K, Cl) & 110 & 65.5 \\
Quantification of urea & 118 & 70.2 \\
Quantification of creatinine substances & 119 & 70.8 \\
Rapid-test dengue NSI Ig & 141 & 83.9 \\
Ultrasonic & 107 & 63.7 \\
Pharmaceutical & & \\
Magnesium gluconate & 83 & 49.4 \\
Probiotics & 53 & 31.5 \\
Clorphenamine $4 \mathrm{mg}$ & 106 & 63.1 \\
Paracetamol $650 \mathrm{mg}$ & 85 & 50.6 \\
Paracetamol $500 \mathrm{mg}$ & 71 & 42.3 \\
\hline
\end{tabular}

creatinine substances, and urea at $83.9 \%, 73.2 \%, 70.8 \%$, and $70.2 \%$, respectively. Meanwhile, tests for electrolytes and ultrasound showed the lowest proportions: $65.5 \%$ and $63.7 \%$, respectively. Chlorpheniramine $4 \mathrm{mg}$ was the most common drug choice (63.1\%). Paracetamol $650 \mathrm{mg}$, magnesium gluconate, paracetamol $500 \mathrm{mg}$, and probiotics followed, with of $50.6 \%, 49.4 \%, 42.3 \%$, and $31.5 \%$, respectively.

According to the data in Table 3, in total the average cost per case was $\$ 139.3 \pm \$ 61.7$. The average cost per child was higher than per adult, but not significant $(\$ 151 \pm \$ 63.5$ and $\$ 132.7 \pm \$ 59.9$, respectively; $P=0.068$ ). The lowest cost per case was $\$ 37.9$, while the highest was $\$ 345.9$. Average direct medical cost, direct nonmedical cost, and indirect cost per case were $\$ 47.1 \pm \$ 31.9, \$ 41.1 \pm \$ 38$, and $\$ 51 \pm \$ 22.7$, respectively. Specifically, the average cost of hospitalization was approximately thrice that of average prehospitalization and posthospitalization, at $\$ 102.7 \pm \$ 49.5, \$ 32.1 \pm \$ 26.5$, and $\$ 31.7 \pm \$ 20.1$, respectively. Results showed the average direct nonmedical cost of child patients was twice that of adults and significant (\$66.6 $\pm \$ 33.1$ and $\$ 27 \pm \$ 33$, respectively; $P<0.001)$.

In prehospitalization period, we estimated the total cost was $\$ 32.1 \pm \$ 26.5$ per case, including $\$ 10.7 \pm \$ 16.4$ for direct medical costs, $\$ 9.5 \pm \$ 10.1$ for direct nonmedical costs, and $\$ 12 \pm \$ 7.7$ for indirect costs. However, average prehospitalization costs for the two groups of different ages in this study were not similar. Specifically, the average direct nonmedical cost of child patients was twice that of adults and significant ( $\$ 16.1 \pm \$ 8.5$ and $\$ 5.8 \pm \$ 9$, respectively; $P=0.025$ ). However, 
Table 3 Mean \pm SD cost per case in prehospitalization, hospitalization, and posthospitalization periods

\begin{tabular}{|c|c|c|c|c|c|}
\hline Age (years) & $\leq 15(n=60)$ & $>15(n=108)$ & $P$-value* & All ages $(n=168)$ & $P$-value** \\
\hline Prehospitalization & & & & & 0.037 \\
\hline Direct medical cost & $10.9 \pm 17.2$ & $10.6 \pm 15.9$ & 0.902 & $10.7 \pm 16.4$ & \\
\hline Direct nonmedical cost & $16.1 \pm 8.5$ & $5.8 \pm 9$ & 0.025 & $9.5 \pm 10.1$ & \\
\hline Indirect cost & $10.5 \pm 6.6$ & $12.8 \pm 8.3$ & $<0.001$ & $12 \pm 7.7$ & \\
\hline Total cost & $37.3 \pm 27$ & $29.1 \pm 25.9$ & 0.08 & $32.1 \pm 26.5$ & \\
\hline Hospitalization & & & & & 0.521 \\
\hline Direct medical cost & $27.7 \pm 31.2$ & $44.1 \pm 26.7$ & $<0.001$ & $38.2 \pm 29.3$ & \\
\hline Direct nonmedical cost & $32.3 \pm 27.6$ & $36.5 \pm 22.4$ & $<0.001$ & $35 \pm 28.2$ & \\
\hline Indirect cost & $48.6 \pm 13.9$ & $18.9 \pm 19.1$ & 0.097 & $29.5 \pm 17.5$ & \\
\hline Total cost & $108.6 \pm 57.5$ & $99.5 \pm 44.5$ & 0.285 & $102.7 \pm 49.5$ & \\
\hline Posthospitalization & & & & & 0.864 \\
\hline Direct medical cost & - & & - & & \\
\hline Direct nonmedical cost & $14.3 \pm 12.9$ & $10.8 \pm 14.3$ & 0.38 & $12 \pm 13.8$ & \\
\hline Indirect cost & $22.8 \pm 14.3$ & $20.5 \pm 13.7$ & 0.601 & $21.3 \pm 13.8$ & \\
\hline Total cost & $35.8 \pm 17$ & $29.5 \pm 21.5$ & 0.252 & $31.7 \pm 20.1$ & \\
\hline Total & & & & & 0.358 \\
\hline Direct medical cost & $36.8 \pm 34$ & $52.9 \pm 29.3$ & 0.002 & $47.1 \pm 31.9$ & \\
\hline Direct nonmedical cost & $66.6 \pm 33.1$ & $26.7 \pm 33$ & $<0.001$ & $41.1 \pm 38$ & \\
\hline Indirect cost & $47.6 \pm 17.3$ & $52.9 \pm 25.1$ & 0.108 & $5 I \pm 22.7$ & \\
\hline Total cost & $151.0 \pm 63.5$ & $132.7 \pm 59.9$ & 0.068 & $139.3 \pm 61.7$ & \\
\hline
\end{tabular}

Notes: *Comparison of average cost between two subgroups ( $\leq 15$ years and $>15$ years); **omparison of average total cost among three periods of treating dengue (rehospitalization, hospitalization, and posthospitalization).

Abbreviation: SD, standard deviation.

the average direct medical cost and the average indirect cost of the two groups of patients were not very different. This led to conformity when the prehospitalization total cost per children was higher than the adult cases. In the hospitalization period, the average cost was $\$ 102.7 \pm \$ 49.5$, of which average direct medical costs, average direct nonmedical costs, and total average indirect costs were $\$ 38.2 \pm \$ 29.3$, $\$ 35 \pm \$ 28.2$, and $\$ 29.5 \pm \$ 17.5$, respectively. In the two groups, the average total costs of hospitalization also showed disparity. Specifically, children's total cost of hospitalization was $\$ 108.6 \pm \$ 57.5$, which was higher than adults' $(\$ 99.5 \pm \$ 44.5)$ $(P=0.285)$. The indirect cost of children in hospital was $\$ 48.6 \pm \$ 13.9$.

In the posthospitalization period, no treatment was reported, yet patients were still not able to work or go to school. Therefore, this led to a change in direct nonmedical cost and indirect cost of $\$ 12 \pm \$ 13.8$ and $\$ 21.3 \pm \$ 13.8$, respectively. Generally, direct medical cost and indirect cost of the child group were lower than those of the adult group, but the direct nonmedical cost was significantly higher $(\$ 66.6 \pm \$ 33.1$ and $\$ 26.7 \pm \$ 33$, respectively; $P<0.001$ ). This result is reasonable for children who cannot take care of themselves and have more nourishment needs.

The components of direct medical cost per patient included $\$ 10.7 \pm \$ 16.4$ for health care services, $\$ 19.4 \pm \$ 19.3$ for hospital-bed cost, $\$ 4 \pm \$ 3.2$ for diagnosis, $\$ 13.5 \pm \$ 8.1$ for the operation, $\$ 5.1 \pm \$ 8.9$ for pharmaceuticals, and $\$ 1 \pm \$ 1.8$ for medical supplies. In total direct medical cost, the cost of a hospital bed was the highest $(\$ 3,224.9)$, in contrast to the cost of medical supplies, which was the lowest (\$134.9) (Table 4). For direct nonmedical cost components, there was transportation cost, meal cost, and caregiver cost: $\$ 3 \pm \$ 5.8$, $\$ 14.6 \pm \$ 7.3$, and $\$ 52.1 \pm \$ 24.9$, respectively.

The costs of a hospital bed, diagnosis, and productivity loss in adults were larger than those of children and significant (respectively: $\$ 22.3 \pm \$ 23.1$ vs $\$ 14.4 \pm \$ 6.7$, $P=0.001 ; \$ 4.4 \pm \$ 2.8$ vs $\$ 3.1 \pm \$ 3.7, P=0.019 ; \$ 52.9 \pm \$ 25.1$ vs $\$ 47.6 \pm \$ 17.3, P=0.108)$. Nevertheless, children had higher meal cost than adults, which was significant $(\$ 18.9 \pm \$ 6.4$ vs $\$ 12.1 \pm \$ 6.7, P<0.001)$. The rest of the average costs did not show any considerable difference between children and adults (Table 4).

\section{Discussion}

The cross-sectional study, which was conducted from September 2015 to March 2016 at $\mathrm{Cu}$ Chi General Hospital, resulted in the successfully calculated treatment cost of DF. The average age of patients was $23.2 \pm 13.3$ years compared to national average ages of $24 \pm 7.2$ years in 2011 and a Pakistan study of $30.4 \pm 13.5$ years. ${ }^{23,28}$ Other studies in Southeast Asia and across four Brazilian regions also shared the commonality of having the same age-group with the highest proportion 
Table 4 Cost per case (mean \pm SD) by cost component $(n=168)$

\begin{tabular}{|c|c|c|c|c|c|c|}
\hline \multirow[t]{2}{*}{ Age (years) } & \multirow[t]{2}{*}{$\leq 15(n=60)$} & \multirow[t]{2}{*}{$>15(n=108)$} & \multirow[t]{2}{*}{$P$-value ${ }^{a}$} & \multicolumn{2}{|l|}{ All ages } & \multirow[t]{2}{*}{$P$-value } \\
\hline & & & & Mean \pm SD & Total $^{\mathrm{b}}(\%)$ & \\
\hline Direct medical cost & & & & & & $<0.001$ \\
\hline Health care service & $10.9 \pm 17.2$ & $10.6 \pm 15.9$ & 0.902 & $10.7 \pm 16.4$ & I,496.2 (6.4) & \\
\hline Hospital bed & $14.4 \pm 6.7$ & $22.3 \pm 23.1$ & 0.001 & $19.4 \pm 19.3$ & $3,224.9(13.8)$ & \\
\hline Diagnosis & $3.1 \pm 3.7$ & $4.4 \pm 2.8$ & 0.019 & $4 \pm 3.2$ & $660(2.8)$ & \\
\hline Operation & $13.4 \pm 1 \mid .9$ & $13.6 \pm 6.6$ & 0.948 & $13.5 \pm 8.1$ & I,558.2 (6.7) & \\
\hline Pharmaceutical & $3.8 \pm 12.8$ & $5.9 \pm 5.7$ & 0.225 & $5.1 \pm 8.9$ & $846.9(3.5)$ & \\
\hline Medical supplies & $0.8 \pm 2.7$ & $I \pm 1.3$ & 0.545 & $I \pm I .8$ & $134.9(0.6)$ & \\
\hline \multicolumn{7}{|c|}{ Direct nonmedical cost } \\
\hline Transport & $2.8 \pm 2.6$ & $3.2 \pm 7$ & 0.589 & $3 \pm 5.8$ & $397.7(1.7)$ & $<0.001$ \\
\hline Meal & $18.9 \pm 6.4$ & $12.1 \pm 6.7$ & $<0.001$ & $14.6 \pm 7.3$ & $2,447.7(10.5)$ & \\
\hline Caregiver & $51.5 \pm 23.6$ & $53.4 \pm 27.9$ & 0.774 & $52.1 \pm 24.9$ & $4,063(17.4)$ & \\
\hline \multicolumn{7}{|l|}{ Indirect cost } \\
\hline Productivity lost & $47.6 \pm 17.3$ & $52.9 \pm 25.1$ & 0.108 & $51 \pm 22.7$ & $8,567.6(36.6)$ & 0.198 \\
\hline Total cost & $|5| \pm 63.5$ & $132.7 \pm 59.9$ & 0.068 & $139.2 \pm 6 \mid .7$ & $23,397.1(100)$ & 0.358 \\
\hline
\end{tabular}

Notes: a Comparison of average cost between two subgroups ( $\leq 15$ years and >15 years); btotal treatment cost of I68 patients; 'comparison of total cost among three cost components of treating dengue (direct medical cost, direct nonmedical cost, and indirect cost).

Abbreviation: SD, standard deviation.

(>15 years old)..$^{29,30}$ This shows the sensitivity of the virus to adapt and escalate with age in the patient's body, despite the weaker immune system and higher susceptibility to viral antigens in children. Nevertheless, adults are more easily exposed to the surrounding environment, as well as the causes of these infections.

Students $(39.9 \%)$ and workers $(32.7 \%)$ were the two groups with the highest rate of infection. This was also found in another study in Vietnam, with an approximate measure of $30 \%$ of infected cases in the worker group. ${ }^{23}$ The percentage of uninsured adults was trivial (3\%); therefore, the awareness of patients of health insurance has been enhanced since 2011 (73\%). Wherever health insurance coverage is high, the treatment cost of dengue in adult patients and their family is significantly reduced, and this suggests a direct impact on the economy and income of patients and their families. Although the percentage of history of dengue was trivial $(7 \%)$, this still proves that dengue may reappear in patients who have had it before. Commonly, an individual's immune system will adapt to and repel whichever virus type has previously intruded the body, yet the chance of cross-infection caused by a different type of virus is possible. The risk of dengue in a human lifetime could quadruple, due to four variants of the dengue virus: DEN1, DEN2, DEN3, and DEN4. ${ }^{1,31}$

The average length of stay per episode was similar to that in a study in Can Tho province in 2012 (2.5, 9.7, and 6 days for prehospitalization, hospitalization, and posthospitalization, respectively) and a study in Cambodia in 2009 (4.8 \pm 1.6 days). ${ }^{4,13}$ In contrast, a study in Pakistan in 2011 showed incomparable lengths of stay in the three stages of treatment (6.25 $\pm 4,6.76 \pm 5$, and $18.89 \pm 9$ days, respectively), but can be explained by the severity of the disease. ${ }^{28}$

The total average cost of treating DF per case among all ages was $\$ 139.2 \pm \$ 61.7$ (79\% of monthly gross domestic product [GDP] in 2015), which was considerably more than the reported results from other studies in Vietnam: \$167.77 (range \$4.5-\$1,208.18) in Can Tho province and \$61.36 (range \$5.34-280.57) in Ho Chi Minh City. ${ }^{13,14}$ However, compared to other countries in Southeast Asia, the cost of treatment in our country was lower: the average cost of treatment in Malaysia was $\$ 863.21$ in $2012(127 \%$ of the 2012 monthly GDP), \$634.87 in Thailand in 2010 (157\% of monthly GDP), and \$3,008.47 in Singapore in 2011 (86\% of monthly GDP).$^{29}$ Our study also found out the average treatment cost per case was $\$ 151 \pm \$ 63.5$ for children $(\leq 15$ years) and $\$ 132.7 \pm \$ 59.9$ for adults ( $>15$ years), with no significant difference $(P>0.05)$. This matches the discovery in another study in Vietnam in which the average cost was $\$ 41$ for children and $\$ 127$ for adults in public hospitals. ${ }^{23}$ Meanwhile, in Cuba the cost of treatment was $\$ 296.60$ per episode (including only hospitalized cases) ${ }^{32}$ In particular, the direct medical cost lower than indirect costs $(28.7 \%$ and $37.2 \%$, respectively), a similarity that was found in a study in Cambodia, but different from other studies around the world. ${ }^{29,33}$ According to other studies, indirect costs are much higher than direct costs, due to the fact that Vietnam and Cambodia are countries with low-average income, ${ }^{2}$ so the cost of productivity loss is less than middle- and highincome countries. 
The Kruskal-Wallis test was conducted to distinguish among these groups in an attempt to conclude significant differences in cost of treatment existed, and the results showed that there was only one difference between having treatment at home before going to hospital; for the rest, there was no difference at all $(P>0.05)$. This means that when patients had treatment before hospitalization, the total cost was lower than for those who did not have prehospitalization treatment $(P=0.037)$. Specifically, indirect costs did not affect treatment elements as understood, as patients considered this cost to be negligible $(P>0.05)$, and whenever hospitalization was necessary, patients were concerned only about the direct $\operatorname{cost}(P<0.001)$.

While comparing the components of cost of treatment, we found that hospital-bed cost took up a large proportion (50.2\%) compared to other components' cost. Therefore, a sensitivity analysis was conducted to estimate the impact of component cost on total treatment cost (Figure 2). Accordingly, if the cost of hospital bed reduced by $10 \%$, the total cost of dengue treatment will fall by $5 \%$, and if the cost for ultrasonic operation also decreased by $10 \%$, treatment costs will undergo a reduction of $1.6 \%$. This result is similar to another on the level of the impact in terms of the total cost of hospital-bed days of treatment for dengue. In Philippines research in 2015, to change the costs/day of a bed from the lowest to the highest level, total costs would fluctuate between $-32 \%$ and $+15 \% .{ }^{34}$ The results of this study can be used as a reference to support health insurance in weighing up the costs at a reasonable rate to reduce the economic burden for patients in the treatment of DF.

\section{Limitations}

Although $\mathrm{Cu}$ Chi district is a hotspot of dengue incidence, the sample size of this study only showed the data of one province and is not representative of the whole of Vietnam. Further, the unit cost of this study was calculated based on Vo et al: ${ }^{24}$ therefore, study data can have some biases but not critical.

\section{Conclusion}

The average cost of treating DF was $\$ 139.27 \pm \$ 61.68$ with inclusion of both direct and indirect costs. Meanwhile, $50.2 \%$ of the total cost was hospital-bed cost. Furthermore, children received cost more in total costs of treatment than adults ( $\$ 151.03 \pm \$ 63.52$ and $\$ 132.73 \pm \$ 59.94$, respectively; $P=0.068)$. With a GDP per capita of $\$ 2,110$ ( $\$ 175.8$ per month), this is a considerable loss for a middling Vietnamese family. This study illustrates that DF is a considerable socioeconomic burden in southern Vietnam. Therefore, the introduction of a potential DF vaccine is impulse the quantification process in the burden of dengue-related diseases, which could only be estimated by conducting a larger scale study with both DF and dengue hemorrhagic fever in several hospitals. This result will be the basis for formulating investment plans and allocating funds for the treatment and prevention of this disease.

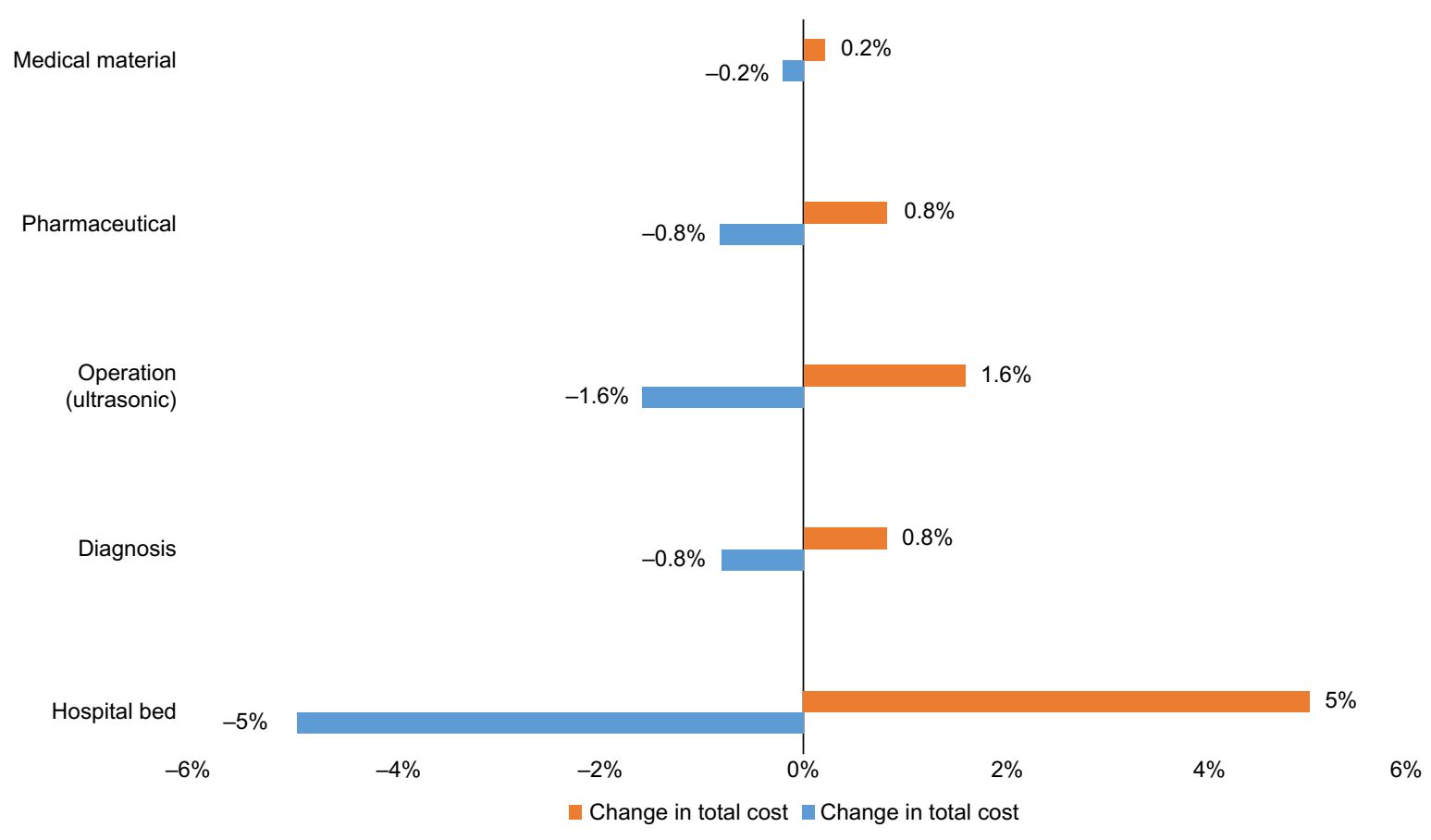

Figure 2 Sensitivity analysis of cost of illness for dengue to change in intensity of care (percentage change in total cost). 


\section{Acknowledgments}

The authors would like to show their appreciation to Ms Phan Ngo Diem Trang for her kind help in this study. Additionally, thanks to the board of directors and the hospital staff of $\mathrm{Cu}$ Chi General Hospital for offering a great opportunity for our research to be conducted at their sites.

\section{Disclosure}

The authors report no conflicts of interest in this work.

\section{References}

1. World Health Organization. Dengue: Guidelines for Diagnosis, Treatment, Prevention, and Control. Geneva: WHO; 2009.

2. Westaway E, Blok J. Taxonomy and evolutionary relationships of flaviviruses. In: Gubler DJ, Kuno G, editors. Dengue and Dengue Hemorrhagic Fever. Wallingford, UK: Centre for Agriculture and Bioscience International; 1997:147-173.

3. Rezza G. Aedes albopictus and the reemergence of dengue. BMC Public Health. 2012;12:72.

4. Huy R, Wichmann O, Beatty M, et al. Cost of dengue and other febrile illnesses to households in rural Cambodia: a prospective communitybased case-control study. BMC Public Health. 2009;9:155.

5. Deen JL, Harris E, Wills B, et al. The WHO dengue classification and case definitions: time for a reassessment. Lancet. 2006;368(9530):170-173.

6. Guzmán MG, Kouri G, Bravo J, Valdes L, Susana V, Halstead SB. Effect of age on outcome of secondary dengue 2 infections. Int J Infect Dis. 2002;6(2):118-124.

7. Guzman MG, Halstead SB, Artsob H, et al. Dengue: a continuing global threat. Nat Rev Microbiol. 2010;8(12 Suppl):S7-S16.

8. Murray NE, Quam MB, Wilder-Smith A. Epidemiology of dengue: past, present and future prospects. Clin Epidemiol. 2013;5:299-309.

9. Pan-American Health Organization. 2002: Number of reported cases of dengue and dengue hemorrhagic fever: region of the Americas (by country and subregion). 2003. Available from: http://www1.paho.org/english/HCP/ HCT/VBD/dengue-cases-2002.htm. Accessed November 28, 2016.

10. Bhatt S, Gething PW, Brady OJ, et al. The global distribution and burden of dengue. Nature. 2013;496(7446):504-507.

11. Vietnam Ministry of Health. [The outbreaks of dengue epidemics in many countries in the region and around the world]. 2015. Available from: http://vncdc.gov.vn/vi/tin-tuc-trong-nuoc/732/dich-benh-sot-xuathuyet-dang-bung-phat-tai-nhieu-quoc-gia-trong-khu-vuc-va-tren-thegioi. Accessed February 19, 2016. Vietnamese.

12. Okanurak K, Sommani S, Indaratna K. The cost of dengue hemorrhagic fever in Thailand. Southeast Asian J Trop Med Public Health. 1997; 28(4):711-717.

13. Tam PT, Dat NT, Huu le M, et al. High household economic burden caused by hospitalization of patients with severe dengue fever cases in Can Tho province, Vietnam. Am J Trop Med Hyg. 2012;87(3):554-558.

14. Harving ML, Rönsholt FF. The economic impact of dengue hemorrhagic fever on family level in southern Vietnam. Dan Med Bull. 2007; 54(2):170-172.
15. Undurraga EA, Betancourt-Cravioto M, Ramos-Castañeda $\mathrm{J}$, et al. Economic and disease burden of dengue in Mexico. PLoS Negl Trop Dis. 2015;9(3):e0003547.

16. Edillo FE, Halasa YA, Largo FM, et al. Economic cost and burden of dengue in the Philippines. Am J Trop Med Hyg. 2015;92(2):360-366.

17. People's Committee of $\mathrm{Cu}$ Chi District. [Essential natural conditions]. 2010. Available from: http://cuchi.hochiminhcity.gov.vn/pages/dieukien-tu-nhien.aspx. Accessed 26 September, 2016. Vietnamese.

18. $\mathrm{Cu} \mathrm{Chi}$ General Hospital. [Cu Chi hospital area introduction]. 2015. Available from: http://bvdkkvcuchi.vn/en/about-us/gioi-thieu-benhvien-37.html. Accessed November 28, 2016. Vietnamese.

19. Kobelt G. Health Economics: An Introduction to Economic Evaluation. 2nd ed. London: Office of Health Economics; 2002.

20. Lemeshow S, Hosmer DW, Klar J, Lwanga SK. Adequacy of Sample Size in Health Studies. Chichester, UK: Wiley; 1990.

21. Julious SA. Sample size of 12 per group rule of thumb for a pilot study. Pharm Stat. 2005;4(4):287-291.

22. World Health Organization. International Statistical Classification of Diseases and Related Health Problems. Geneva: WHO; 2004.

23. Nguyen Thi Kim Tien. Chi phi dieu tri benh sot dengue/sot xuat huyet dengue tai benh vien. Report on The Ministry of Health Research Project. HCMC Pasteur Institute: Ministry of Health. 2011. Available from http://text.123doc.org/document/1305966-chi-phi-dieu-tri-benhsot-dengue-sot-xuat-huyet-dengue-tai-benh-vien.htm.

24. Trung QV, Minh VH, Huong TN, Riewpaiboon A. Hospital service cost analysis in developing countries: a method comparison in Vietnam. In press 2016.

25. Altman DG. Practical Statistics for Medical Research. Boca Raton (FL): CRC Press; 1990.

26. Miller JP. Essential Statistical Methods for Medical Statistics. Burlington (MA): Elsevier; 2010.

27. State Bank of Vietnam. Central rate of VND versus USD. 2016. Available from: http://www.sbv.gov.vn/webcenter/portal/vi/menu/rm/tg?_afrLoop $=2034115526220912 \# ! \% 40 \% 40 \% 3 F \_$afrLoop $\% 3 D 203411552622091$ 2\%26centerWidth\%3D80\%2525\%26leftWidth\%3D20\%2525\%26right Width\%3D0\%2525\%26showFooter\%3Dfalse \%26showHeader\%3Dfa 1se\%26_adf.ctrl-state\%3D14hrlz2ubh_49. Accessed March 30, 2016.

28. Rafique I, Saqib MA, Munir MA, et al. Economic burden of dengue in four major cities of Pakistan during 2011. JPakMedAssoc. 2015;65(3):256-259.

29. Shepard DS, Undurraga EA, Halasa YA. Economic and disease burden of dengue in Southeast Asia. PLoS Negl Trop Dis. 2013;7(2):e2055.

30. Martelli CM, Junior JB, Parente MP, et al. Economic impact of dengue: multicenter study across four Brazilian regions. PLoS Negl Trop Dis. 2015;9(9):e0004042.

31. Messer WB, Gubler DJ, Harris E, Sivananthan K, De Silva AM. Emergence and global spread of a dengue serotype 3, subtype III virus. Emerg Infect Dis. 2003;9(7):800-809.

32. Durham DP, Mbah ML, Medlock J, et al. Dengue dynamics and vaccine cost-effectiveness in Brazil. Vaccine. 2013;31(37):3957-3961.

33. Constenla D, Garcia C, Lefcourt N. Assessing the economics of dengue: results from a systematic review of the literature and expert survey. Pharmacoeconomics. 2015;33(11):1107-1135.

34. Weaver SC, Vasilakis N. Molecular evolution of dengue viruses: contributions of phylogenetics to understanding the history and epidemiology of the preeminent arboviral disease. Infect Genet Evol. 2009;9(4):523-540.
ClinicoEconomics and Outcomes Research

\section{Publish your work in this journal}

ClinicoEconomics and Outcomes Research is an international, peerreviewed open-access journal focusing on health technology assessment, pharmacoeconomics and outcomes research in the areas of diagnosis, medical devices, and clinical, surgical and pharmacological intervention. The economic impact of health policy and health systems

\section{Dovepress}

organization also constitute important areas of coverage. The manuscript management system is completely online and includes a very quick and fair peer-review system, which is all easy to use. Visit http://www.dovepress.com/testimonials.php to read real quotes from published authors. 